\title{
The impact of gender and working hours on pulmonary physician burnout
}

\author{
Ying Zhou ${ }^{1 \#}$, Weiqing Gu ${ }^{2 \#}$, Rong Tao ${ }^{3}$, Chang Chen ${ }^{4}$ \\ ${ }^{1}$ Department of Respiratory Medicine and Clinical Research Center, ${ }^{2}$ Department of Respiratory Medicine, Shanghai Pulmonary Hospital, \\ Tongji University School of Medicine, Shanghai, China; ${ }^{3}$ Shanghai Pulmonary Hospital, Tongji University School of Medicine, Shanghai, China; \\ ${ }^{4}$ Department of Thoracic Surgery, Shanghai Pulmonary Hospital, Tongji University School of Medicine, Shanghai, China \\ Contributions: (I) Conception and design: C Chen, R Tao, Y Zhou; (II) Administrative support: C Chen, R Tao; (III) Provision of study materials or \\ patients: Y Zhou, W Gu; (IV) Collection and assembly of data: Y Zhou, W Gu; (V) Data analysis and interpretation: Y Zhou, W Gu; (VI) Manuscript \\ writing: All authors; (VII) Final approval of manuscript: All authors. \\ "These authors contributed equally to this work. \\ Correspondence to: Chang Chen. Department of Thoracic Surgery, Shanghai Pulmonary Hospital, Tongji University School of Medicine, 507 \\ Zhengmin Road, Shanghai, China. Email: Chenthoracic@163.com; Rong Tao. Shanghai Pulmonary Hospital, Tongji University School of Medicine, \\ 507 Zhengmin Road, Shanghai, China. Email: 18930177100@126.com.
}

Background: Physician burnout has attracted an increasing amount of attention as a global public health problem. It is associated with negative clinical and organizational outcomes, including lower patient satisfaction, patient safety, and quality of care. The work of pulmonary physicians involves high levels of stress, putting them at higher risk of burnout. This study aimed to evaluate the personal and professional characteristics associated with burnout among pulmonary physicians.

Methods: Between March 2020 and May 2020, a survey to evaluate burnout and career satisfaction among pulmonary physicians was conducted in Shanghai Pulmonary Hospital. The survey collected information on physician characteristics, career satisfaction, and burnout. The Maslach Burnout Inventory (MBI), the gold standard tool for measuring burnout, was used to measure burnout symptoms. Self-reported professional satisfaction in relation to career, specialty, and work-life balance was recorded.

Results: Of 130 pulmonary physicians contacted, 125 (96.1\%) completed full-length surveys. Ninetyone $(72.8 \%)$ of these 125 physicians were female. The survey participants had a median age of 40 years. Of the respondents, $48.8 \%$ had at least one symptom of burnout according to high emotional exhaustion (EE) score and/or high depersonalization (DP) score. Univariable analysis showed female gender, the number hours worked per week, the number of nights on call per month, and the number of calls per night shift to be factors associated with burnout. Gender and hours worked per week were independent factors associated with burnout in multivariate analysis.

Conclusions: The MBI was able to characterize burnout experienced by pulmonary physicians in our hospital. Gender and the number of hours worked per week were the significant factors independently associated with burnout among the physicians in our study.

Keywords: Burnout; pulmonary physician; career satisfaction

Submitted Jul 13, 2020. Accepted for publication Sep 04, 2020.

doi: $10.21037 / \mathrm{atm}-20-5827$

View this article at: http://dx.doi.org/10.21037/atm-20-5827 


\section{Introduction}

Burnout is a psychological syndrome frequently experienced by healthcare professionals. It includes three dimensions: emotional exhaustion (EE), depersonalization (DP), and low personal accomplishment (PA). EE is a condition in which an individual has decreased emotional energy to meet work-related demands due to high levels of stress; DP is defined as emotional distance from one's job; and low PA refers to a feeling of negative self-worth in relation to one's work (1).

Physician burnout is drawing an increasing amount of attention and, with an incidence that has significantly increased in the past decade, constitutes a global public health problem $(2,3)$. Physician burnout is associated with high risk of medical errors and high turnover rate of physicians. A large-scale national study in America suggested that physician burnout was closely related to major medical errors. More than $10 \%$ of respondents reported a major medical error in the past three month, and physicians reporting errors were more likely to have symptoms of burnout (4). Another survey found more than $15 \%$ of surgeons who experienced high levels of emotional exhaustion and depersonalization reported at least one major medical error in the past three months, which tripled the error rate of those with the lowest level of burnout (5). In addition, physician burnout may lead to high turnover rate, affecting the medical services of patients. Sinsky et al. reported about $26.6 \%$ of physicians would leave their current practice in the next 2 years. Their intention to leave medicine is highly correlated with burnout (6).

Pulmonary physicians have long working hours, manage lots of critical patients, experience high levels of stress, and are responsible for handling some infectious diseases especially in COVID-19 epidemic situation. These factors place pulmonary physicians at high risk of burnout. Although the impact of burnout in healthcare professionals of oncologists, surgeons, and pediatric residents has already been explored (7-9), little is known about demographic and professional characteristics associated with burnout and professional satisfaction among pulmonary physicians. With growing evidence that physician burnout negatively impacts both the quality of doctors' performance and patient safety by contributing to medical errors, identifying the common causes of burnout among physicians is of great importance. This study aimed to determine the prevalence of burnout among pulmonary physicians in Shanghai Pulmonary Hospital, and to examine the association between burnout and the demographic and professional characteristics of the physicians.

We present the following article in accordance with the SURGE reporting checklist (available at http://dx.doi. org/10.21037/atm-20-5827).

\section{Methods}

\section{Participants}

An electronic survey was sent to 130 pulmonary physicians in March, 2020, with a reminder request sent 3 weeks later. Participation was voluntary and anonymous. Informed consent was taken from all the participants. The institutional ethics committee of Shanghai Pulmonary Hospital approved the study (No. K20-308). The study was conducted in accordance with the Declaration of Helsinki (as revised in 2013).

\section{Study measures}

The survey included items covering demographic characteristics, professional characteristics, burnout, career satisfaction, and satisfaction with work-life balance (WLB).

Burnout was measured according to the Maslach Burnout Inventory (MBI), the gold-standard tool for measuring burnout, with a validated questionnaire comprising 22 items (1). First developed by Maslach in 1981, the MBI is widely used in academic research on burnout. It contains 22 items across the 3 following subscales: EE, DP, and PA (Table S1). The items are answered by the respondent based on the frequency at which they experience these feelings. The responses are scored using a 7-point anchored scale, ranging from 0 ("never") to 6 ("every day"). In the standard scoring criteria for medical workers, scores of $\geq 27$ on the EE subscale, $\geq 10$ on the DP subscale, or $<33$ on the PA subscale are considered to show a high degree of burnout in that dimension (1). According to accepted standards, physicians with a high score on the DP and/or EE subscales of the MBI are considered to have at least one manifestation of professional burnout $(7,10-12)$.

The professional satisfaction survey included three different dimensions: career satisfaction, specialty satisfaction, and satisfaction with WLB. In terms of career satisfaction, the physicians were asked whether they would choose to become a physician if they had the opportunity to revisit their career choice. In terms of specialty satisfaction, the physicians were asked whether they would choose 
Table 1 Demographic characteristics of 125 pulmonary physicians

\begin{tabular}{|c|c|c|c|c|}
\hline Characteristics & $\begin{array}{l}\text { All }(n=125), \\
\text { no. }(\%)\end{array}$ & $\begin{array}{c}\text { With burnout }(n=61) \text {, } \\
\text { no. }(\%)\end{array}$ & $\begin{array}{l}\text { Without burnout }(n=64) \text {, } \\
\text { no. }(\%)\end{array}$ & $P$ \\
\hline Age, years & & & & NA \\
\hline$<30$ & $9(7.2)$ & $3(4.9)$ & $6(9.4)$ & \\
\hline$\geq 50$ & $20(16.0)$ & $11(18.0)$ & $9(14.1)$ & \\
\hline Gender & & & & 0.025 \\
\hline Female & $91(72.8)$ & $50(82.0)$ & $41(64.1)$ & \\
\hline 1 & $77(61.6)$ & 39 (63.9) & $38(59.4)$ & \\
\hline 2 & $24(19.2)$ & $13(21.3)$ & $11(17.2)$ & \\
\hline Relationship status & & & & NA \\
\hline Single & $13(10.4)$ & 5 (8.19) & $8(12.5)$ & \\
\hline Married & $108(86.4)$ & $54(88.5)$ & $54(84.4)$ & \\
\hline Divorced & $4(3.2)$ & $2(3.3)$ & $2(3.1)$ & \\
\hline
\end{tabular}

the same specialty again if they had the opportunity to revisit their specialty choice (13). "Yes" was considered to indicate greater career or specialty satisfaction, and "no" was considered to indicate dissatisfaction with the career or specialty. To determine WLB satisfaction, the physicians were asked if they agreed with the statement "My work schedule leaves me enough time for my personal/family life" (14). "Agree" was considered to show satisfaction with the WLB, and "disagree" was regarded as showing dissatisfaction with the WLB.

\section{Statistical analysis}

Associations between continuous variables were evaluated using the Student's $t$-test or analysis of variance (ANOVA), and categorical variables were evaluated using the $\chi^{2}$ test. Multivariable logistic regression analysis was carried out to identify demographic and professional characteristics associated with burnout and professional satisfaction. All statistical analyses were conducted using the SPSS 22.0 software package (SPSS, Inc., Chicago, IL, USA).

\section{Results}

\section{Demographic and professional characteristics}

Of 130 pulmonary physicians invited to participate, 125 (96.1\%) completed the survey. Table 1 summarizes he demographic characteristics of the participants. Ninetyone $(72.8 \%)$ of the 125 physicians who responded were female. The participants had a median age of 40 years. The majority of respondents (86.4\%) were married, and $80.8 \%$ had children. Table 2 details the physicians' professional characteristics. The median time spent in clinical practice was 14 years. The pulmonary physicians dedicated a median of 50.0 hours (range, 40-90 hours) per week to professional activities, with the majority working fewer than 60 hours $(73.6 \%)$.

\section{Burnout}

Table 3 summarizes burnout and professional satisfaction among the 125 pulmonary physicians who participated in our survey. The participants were assessed using the 
Table 2 Professional characteristics of 125 pulmonary physicians

\begin{tabular}{|c|c|c|c|c|}
\hline Characteristics & $\begin{array}{c}\text { All }(n=125) \\
\text { no. }(\%)\end{array}$ & $\begin{array}{c}\text { With burnout }(\mathrm{n}=61) \text {, } \\
\text { no. }(\%)\end{array}$ & $\begin{array}{l}\text { Without burnout }(n=64) \text {, } \\
\text { no. }(\%)\end{array}$ & $\mathrm{P}$ \\
\hline Years in practice & & & & NA \\
\hline Median & 14 years & 15 years & 13 years & \\
\hline$<10$ & $43(34.4)$ & $17(27.9)$ & $26(40.6)$ & \\
\hline$\geq 20$ & $30(24.0)$ & $14(22.9)$ & $16(25.0)$ & \\
\hline Educational background & & & & NA \\
\hline Bachelor's degree & $20(16.0)$ & $8(13.1)$ & $12(18.8)$ & \\
\hline Master's degree & $57(45.6)$ & $34(55.7)$ & $23(35.9)$ & \\
\hline $40-49$ & $45(36.0)$ & $16(26.2)$ & $29(45.3))$ & \\
\hline $50-59$ & $47(37.6)$ & $26(42.6)$ & $21(32.8)$ & \\
\hline $60-69$ & $21(16.8)$ & $9(14.7)$ & $12(18.8)$ & \\
\hline$\geq 70$ & $12(9.6)$ & $10(16.4)$ & $2(3.1)$ & \\
\hline \multicolumn{5}{|l|}{ No. of nights on call per month } \\
\hline Mean \pm SD & $3.5 \pm 1.8$ & $3.8 \pm 1.8$ & $3.1 \pm 1.7$ & \\
\hline$<4$ & $52(41.6)$ & $19(31.1)$ & $33(51.6)$ & 0.015 \\
\hline$\geq 2$ & $70(56.0)$ & $40(65.6)$ & $30(46.9)$ & \\
\hline No. of outpatients in clinic per week & & & & NA \\
\hline Mean \pm SD & $84.6 \pm 63.3$ & $86.8 \pm 55.9$ & $82.5 \pm 70.0$ & \\
\hline No. of inpatients per week & & & & NA \\
\hline Mean \pm SD & $34.7 \pm 36.5$ & $37.7 \pm 37.0$ & $32.0 \pm 36.1$ & \\
\hline
\end{tabular}

MBI with a 22-item questionnaire; the median score of EE, DP and PA was 25, 5 and 38 respectively. $44.8 \%$ of the physicians scored highly for emotional exhaustion, $27.2 \%$ scored highly for DP, and $28.8 \%$ had a low sense of PA. As described above, physicians with a high score on the DP subscale and/or the EE subscale of the MBI were considered as having at least one manifestation of professional burnout. Of the respondents, $48.8 \%$ had at least one symptom of burnout based on this standard. Table 1 shows the various demographic characteristics associated with burnout in univariate analysis. A significantly higher proportion of female physicians $(56.6 \%$, 50/91) had burnout symptoms than male physicians $(32.3 \%$, 11/34) $(\mathrm{P}=0.025)$. Female physicians were more likely 
than male physicians to experience burnout. In univariate analysis, professional characteristics associated with burnout included the number of hours worked per week, the number of nights on call per month, and the number of calls per night shift (Table 2, Figure 1).

\section{Professional satisfaction}

Career satisfaction was reported by 77 (61.6\%) of the physicians in our study and the same proportion of the physicians had specialty satisfaction (Table 3). Satisfaction with career choice and satisfaction with specialty choice were lower in the burnout group $(\mathrm{P}<0.001)$. Only 31 (24.8\%) physicians felt that their work schedule left enough time for personal/family life (Table 3). In the physicians in our study, lower WLB satisfaction was associated with burnout $(\mathrm{P}<0.001)$.

\section{Multivariable analysis}

A binary logistic regression analysis was performed incorporating the factors that were associated with burnout $(\mathrm{P}<0.05)$ in the univariate analysis; these included gender, the number of hours worked per week, the number of nights on call per month, and the number of calls per night shift (Table 4). Female gender and the number of hours worked per week were found to be independent factors associated with burnout in the pulmonary physicians in our study.

\section{Discussion}

Burnout has been observed in medical professionals at all stages of their careers, from medical students to practicing physicians. Approximately $48.8 \%$ of the pulmonary

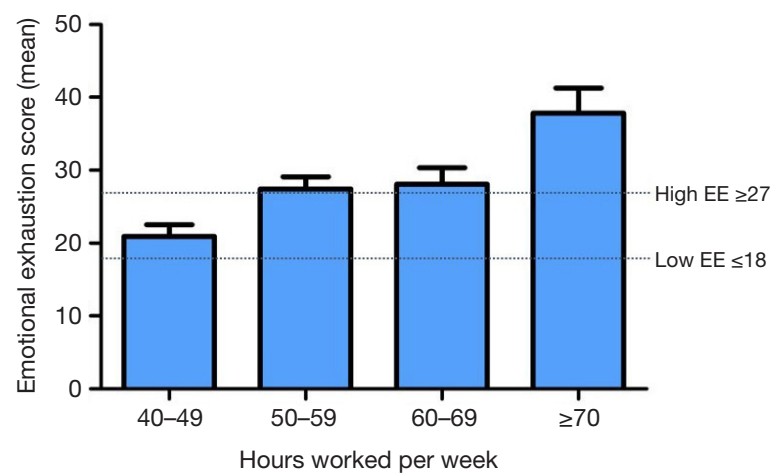

physicians who participated in this study reported burnout in their career. The burnout rate in this study was similar to that in a previous study, which estimated $50 \%$ of US physicians to have experienced at least one symptom of burnout $(14,15)$. Burnout is more common in some specialties, there is $60-70 \%$ of physicians reported burnout in emergency medicine and about $50-60 \%$ in primary

Table 3 Physician burnout and professional satisfaction

\begin{tabular}{ll}
\hline Variable & No. (\%) \\
\hline Burnout indices & \\
Emotional exhaustion & $34(27.2)$ \\
Low score & $35(28.0)$ \\
Intermediate score & $56(44.8)$ \\
High score & \\
Depersonalization & $67(53.6)$ \\
Low score & $24(19.2)$ \\
Intermediate score & $34(7.2)$ \\
High score & \\
Personal accomplishment & $36(28.8)$ \\
Low score & $41(32.8)$ \\
Intermediate score & $48(38.4)$ \\
High score & $61(48.8)$ \\
Burned out & $77(61.6)$ \\
Dimensions of professional satisfaction & \\
Career satisfaction & \\
Specialty satisfaction & \\
\hline
\end{tabular}

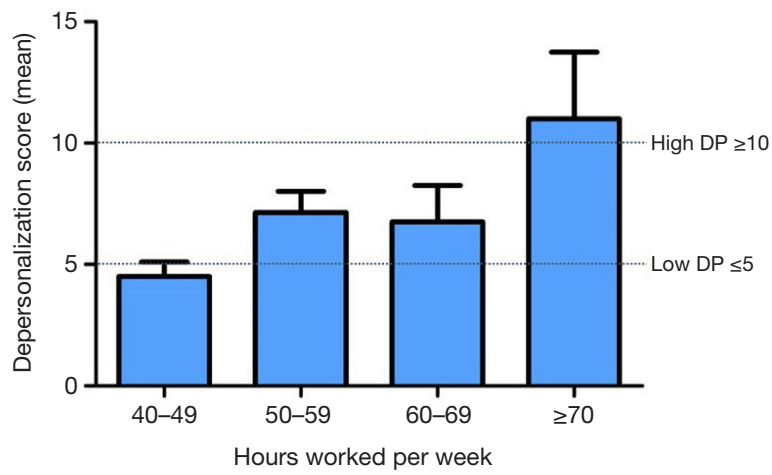

Figure 1 Relationship between patient care hours and burnout among 125 pulmonary physicians. 
Table 4 Multivariable regression analysis of pulmonary physician burnout

\begin{tabular}{lccc}
\hline Univariate factor & OR & $95 \% \mathrm{Cl}$ & $\mathrm{P}$ \\
\hline Gender & 2.893 & $1.204-6.955$ & 0.018 \\
No. of hours worked per week & 1.044 & $1.003-1.087$ & 0.035 \\
No. of nights on call per month & 1.237 & $0.960-1.593$ & 0.101 \\
No. of calls per night shift & 1.041 & $0.811-1.338$ & 0.751 \\
\hline
\end{tabular}

health care, while it is relatively low in dermatology department $(30-40 \%)(14,16)$. The etiology of burnout among physicians in different department is multifactorial, with contributing factors including female gender, younger age, poor work-life balance, longer working hours, more nights on call and private practice $(17,18)$.

The number of practicing physicians who are women is growing. However, many papers have reported that female doctors are more susceptible to burnout. In this study, we observed that burnout among pulmonary physicians was strongly related to gender. Although our cross-sectional study could not determine the nature of this association, the risk of female pulmonary physicians developing burnout was 1.7 times that of males. Other surveys have reported that female physicians to have a $20-60 \%$ higher rate of burnout than male physicians (19). Smaller specialty-specific studies have also supported the view that women are more likely to suffer from burnout $(20,21)$. Female physicians face genderspecific challenges in their work. Women are faced with the issues of having limited childbearing years and being the main caregivers for children. They also receive fewer opportunities for promotion to leadership positions, and still encounter unequal pay (22). With more work-related stressors and less control over their working environment, female physicians are generally less satisfied with their careers (23).

Some studies have observed a correlation between working hours and burnout; however, a consensus on the relationship between the two has yet to be reached. Our study found that the prevalence of burnout among pulmonary physicians was significantly associated with longer working hours. Stodel and Stewart-Smith's findings supported this hypothesis (24). Their study showed that workload was the most important cause of burnout, accounting for $26 \%$ of cases, while long working hours was the third most significant cause, being responsible for $16 \%$ of cases. Arigoni et al.'s study on burnout in doctors in
Switzerland focused on three different specialties: general practitioners, pediatricians, and cancer physicians (25). The results showed that doctors who worked over 50 hours a week were at high risk in two of the three aspects of burnout defined by the MBI, making them more likely to suffer from the condition. It was concluded that long-term work could predict the job burnout in this study.

Our study has several limitations. Due to the survey's cross-sectional nature, we were unable to determine the potential direction of the cause-effect relationship for the associations observed. Some bias may have been caused by the small number of participants, single center study and the predominance of female physicians in this group. Therefore, caution must be applied when attempting to generalize the findings of this study to other settings.

In conclusion, gender and the number of hours worked per week were the significant factors associated with burnout among the pulmonary physicians in our study. The impact of burnout on physicians should not be underestimated. Many associated factors, such as long working hours, could potentially be addressed. We hope that our findings will emphasize the importance of evidence-based management practices and help to address some of the causes of burnout in physicians. Further work is needed to develop a prospective study for predictors with cause-effect relationships in physician burnout.

\section{Acknowledgments}

Funding: This work was supported by grants from National Science Foundation of Shanghai, China (No. 18ZR1431400).

\section{Footnote}

Reporting Checklist: The authors have completed the SURGE reporting checklist. Available at http://dx.doi. org/10.21037/atm-20-5827

Data Sharing Statement: Available at http://dx.doi. org/10.21037/atm-20-5827

Conflicts of Interest: All authors have completed the ICMJE uniform disclosure form (available at http://dx.doi. org/10.21037/atm-20-5827). The authors have no conflicts of interest to declare.

Ethical Statement: The authors are accountable for all 
aspects of the work in ensuring that questions related to the accuracy or integrity of any part of the work are appropriately investigated and resolved. Informed consent was taken from all the participants. The institutional ethics committee of Shanghai Pulmonary Hospital approved the study (No. K20-308). The study was conducted in accordance with the Declaration of Helsinki (as revised in 2013).

Open Access Statement: This is an Open Access article distributed in accordance with the Creative Commons Attribution-NonCommercial-NoDerivs 4.0 International License (CC BY-NC-ND 4.0), which permits the noncommercial replication and distribution of the article with the strict proviso that no changes or edits are made and the original work is properly cited (including links to both the formal publication through the relevant DOI and the license). See: https://creativecommons.org/licenses/by-nc-nd/4.0/.

\section{References}

1. Jackson SE, Leiter MP, Maslach C. Maslach burnout inventory manual. 3rd ed. ed. Palo Alto, Calif.: Consulting Psychologists Press; 1996.

2. Wright AA, Katz IT. Beyond Burnout - Redesigning Care to Restore Meaning and Sanity for Physicians. N Engl J Med 2018;378:309-11.

3. Ariely D, Lanier WL. Disturbing Trends in Physician Burnout and Satisfaction With Work-Life Balance: Dealing With Malady Among the Nation's Healers. Mayo Clinic Proceedings 2015;90:1593-6.

4. Tawfik DS, Profit J, Morgenthaler TI, et al. Physician Burnout, Well-being, and Work Unit Safety Grades in Relationship to Reported Medical Errors. Mayo Clin Proc 2018;93:1571-80.

5. Dyrbye LN, Varkey P, Boone SL, et al. Physician satisfaction and burnout at different career stages. Mayo Clin Proc 2013;88:1358-67.

6. Sinsky CA, Dyrbye LN, West CP, et al. Professional Satisfaction and the Career Plans of US Physicians. Mayo Clin Proc 2017;92:1625-35.

7. Shanafelt TD, Bradley KA, Wipf JE, et al. Burnout and self-reported patient care in an internal medicine residency program. Ann Intern Med 2002;136:358-67.

8. Baer TE, Feraco AM, Tuysuzoglu Sagalowsky S, et al. Pediatric Resident Burnout and Attitudes Toward Patients. Pediatrics 2017;139:e20162163.

9. Shanafelt TD, Raymond M, Kosty M, et al. Satisfaction with work-life balance and the career and retirement plans of US oncologists. J Clin Oncol 2014;32:1127-35.

10. Rosen IM, Gimotty PA, Shea JA, et al. Evolution of sleep quantity, sleep deprivation, mood disturbances, empathy, and burnout among interns. Acad Med 2006;81:82-5.

11. Thomas NK. Resident burnout. JAMA 2004;292:2880-9.

12. Dyrbye LN, West CP, Shanafelt TD. Defining burnout as a dichotomous variable. J Gen Intern Med 2009;24:440-1.

13. Kuerer HM, Eberlein TJ, Pollock RE, et al. Career satisfaction, practice patterns and burnout among surgical oncologists: report on the quality of life of members of the Society of Surgical Oncology. Ann Surg Oncol 2007;14:3043-53.

14. Shanafelt TD, Boone S, Tan L, et al. Burnout and satisfaction with work-life balance among US physicians relative to the general US population. Arch Intern Med 2012;172:1377-85.

15. Dyrbye LN, West CP, Satele D, et al. Burnout among U.S. medical students, residents, and early career physicians relative to the general U.S. population. Acad Med 2014;89:443-51.

16. Squiers JJ, Lobdell KW, Fann JI, et al. Physician Burnout: Are We Treating the Symptoms Instead of the Disease? Ann Thorac Surg 2017;104:1117-22.

17. Dimou FM, Eckelbarger D, Riall TS. Surgeon Burnout: A Systematic Review. J Am Coll Surg 2016;222:1230-9.

18. Mendelsohn D, Despot I, Gooderham PA, et al. Impact of work hours and sleep on well-being and burnout for physicians-in-training: the Resident Activity Tracker Evaluation Study. Med Educ 2019;53:306-15.

19. McMurray JE, Linzer M, Konrad TR, et al. The work lives of women physicians results from the physician work life study. The SGIM Career Satisfaction Study Group. J Gen Intern Med 2000;15:372-80.

20. Shenoi AN, Kalyanaraman M, Pillai A, et al. Burnout and Psychological Distress Among Pediatric Critical Care Physicians in the United States. Crit Care Med 2018;46:116-22.

21. Shanafelt TD, Gradishar WJ, Kosty M, et al. Burnout and career satisfaction among US oncologists. J Clin Oncol 2014;32:678-86.

22. Robinson GE. Stresses on women physicians: consequences and coping techniques. Depress Anxiety 2003;17:180-9.

23. Frank E, McMurray JE, Linzer M, et al. Career satisfaction of US women physicians: results from the 
Page 8 of 8

Women Physicians' Health Study. Society of General Internal Medicine Career Satisfaction Study Group. Arch Intern Med 1999;159:1417-26.

24. Stodel JM, Stewart-Smith A. The influence of burnout on skills retention of junior doctors at Red Cross War Memorial Children's Hospital: a case study. S Afr Med J 2011;101:115-8.

Cite this article as: Zhou $\mathrm{Y}, \mathrm{Gu} \mathrm{W}$, Tao R, Chen $\mathrm{C}$. The impact of gender and working hours on pulmonary physician burnout. Ann Transl Med 2020;8(18):1166. doi: 10.21037/atm20-5827

\section{Zhou et al. Impact factors on pulmonary physician burnout}

25. Arigoni F, Bovier PA, Mermillod B, et al. Prevalence of burnout among Swiss cancer clinicians, paediatricians and general practitioners: who are most at risk? Support Care Cancer 2009; 17:75-81.

(English Language Editor: J. Reynolds) 


\section{Supplementary}

Table S1 Maslach Burnout Inventory (MBI) items

Emotional exhaustion (EE) subscale

1 Feel emotionally drained from work

2 Feel used up at the end of the workday

3 Feel fatigued when getting up in the morning

20 Feel like at the end of the rope

8 Feel burned out from work

13 Feel frustrated by job

14 Feel working too hard on the job

6 Working with people puts too much stress

16 Working with patients is a strain

Depersonalization (DP) subscale

5 Treat patients as impersonal "objects"

10 Become more callous toward people

11 Worry that job is hardening emotionally

15 Don't really care what happens to patients

22 Feel patients blame for their problems

Personal accomplishment (PA) subscale

4 Can easily understand patients' feelings

7 Deal effectively with the patients' problems

9 Feel positively influencing people's lives

12 Feel very energetic

17 Can easily create a relaxed atmosphere

18 Feel exhilarated after working with patients

19 Have accomplished worthwhile things in job

21 Deal with emotional problems calmly 